\title{
Discussion on EQ Education for College Students
}

\author{
Yuangui $\mathrm{Li}^{1}$ \\ ${ }^{1}$ Chengdu Textile College, Chengdu, Sichuan, China \\ Correspondence: Yuangui Li, Department of Higher Education Research and Development Planning, Chengdu \\ Textile College, Chengdu, Sichuan, 611731, China. Tel: 86-136-6620-9291
}

Received: November 12, 2013 Accepted: December 2, 2013 Online Published: December 21, 2013

doi:10.5430/sass.v1n1p44 URL: http://dx.doi.org/10.5430/sass.v1n1p44

\begin{abstract}
Emotional Quotient (referred to as EQ), as a kind of non-intelligence factor, is of great importance to one's success in their careers. The paper focuses on the following three points: the connotation of $\mathrm{EQ}$, the significance of strengthening students' EQ education, and also putting forward some methods to improve the education level of College Students' Emotional Quotient.

Keywords: College Students, EQ (Emotional Quotient), education

\section{Introduction}

Emotional Quotient is a key factor in the growing process of the college students. Contemporary college students are the main force to realize the great rejuvenation of China, shouldering the great responsibility of historical mission and the people. The EQ level of contemporary college students will not only affect their learning, life and body and mental health, but also affect the quality of the whole nation and national prosperity. Therefore, strengthening the college students' EQ education, improving college students' EQ level, is an important subject of higher education, which should be the concern of the whole society.
\end{abstract}

\section{Connotation of EQ}

In 1995, American psychologist Daniel Goleman proposed the concept of "Emotional Quotient (EQ)" in Emotional Intelligence. It is thought that Emotional Quotient is an important individual ability for survival; it is a key factor that could dig the emotional potential, affect the life of each level and the future life through the ability to use emotional intelligence. In the elements of one's success, mental factors are important, but more important one is emotional factors. Emotional Quotient includes the ability in five aspects: the ability for understanding their own emotions, the ability to manage emotions properly, the ability of self-motivated, the ability of cognitive emotion, and the ability on interpersonal communication.

Emotional Quotient (EQ), also known as "emotional intelligence", is proposed relatively to the IQ (Intelligence Quotient, referred to as IQ). Intelligence Quotient (IQ) is the determination of one's intelligence factors, while EQ is the determination of the non-intellectual factors of a person. Intelligence is a kind of comprehensive cognitive ability, and its basic elements include attention, observation, memory, imagination and thinking ability. Among the five elements, thinking ability is the core of intelligence. The non-intelligence factor is a general term of all factors except intelligent factor in people's activities, mainly consisting of the following elements: interest, motivation, beliefs, emotion, ideal, will, character and other factors. The non-intelligence factor is a comprehensive quality in the process of people's practical activities; emotion and will are some of the more active factors, which play a dynamic, strengthening role.

Emotional Quotient, as a kind of non-intelligence factors, is of great importance to one's career success. The research result of psychologist Daniel Goleman shows that, Intelligence Quotient accounted only for $20 \%$ in the affecting factors in the personnel success, while the $80 \%$ is attributed to the Emotional Quotient. As American educator Carnegie said, in the success of a person, only $15 \%$ is relied on his professional knowledge, while $85 \%$ on the excellent ability for interpersonal relationship. There is another saying: people's success, $20 \%$ relied on intelligence, $20 \%$ by chance, while $60 \%$ is attributed to his Intelligence Quotient. An authoritative survey institution in the western countries used to publish such a survey result: people in almost all areas of the world, such as the famous scientists, political leaders, business tycoons and so on, the key factor that plays a decisive role in their success, is not the intelligence factor, but the non-intellectual factors. In other words, the reason for their success, is not their 
outstanding intelligence, but because of their excellent Emotional Quotient.

\section{The Significance of Strengthening Students' EQ Education}

\subsection{EQ is Beneficial to Promote the Intellectual Development of College Students}

College Students are in the transition occasion of intellectual growth and peak, and in the golden age of intellectual development. Contemporary society has entered to the era of knowledge economy, knowledge updates more and more quickly. This requires the students to have the ability to acquire and maintain knowledge, the more important is that they should have valuable pioneering spirit and innovation ability to operate creative thinking. In the students' thinking activities, emotional intelligence plays an important promoting role. First of all, the EQ have the function of choice and guidance in college students thinking activities; secondly, EQ can promote and support students' thinking activity, making the student's brain in the best active status, open-minded, and could carry on the ponder, from the point of view through breaking the stereotype, develop their potential, so as to operate creative thinking.

\subsection{EQ is Beneficial to the Perfection of Personality}

Personality is an important part of the quality of a person, and it is composed of many interacting, constantly changing part. The stage in university is an important period of developing, restructuring, perfecting one's personality. EQ will encourage students, to a certain extent, to mature self-awareness, to help students recognize changes and challenges in the development of themselves in an active, good, stable emotional state, so as to obtain self-consistent psychological feelings; EQ is helpful to the shaping of good characters of the students, and it could help students to cultivate optimistic upward, positive enterprising, indomitable quality and sincere, friendly, generous, considerate, good character; EQ is also conducive to enhance students' tolerance. It may control negative emotions, and then make it into a positive, healthy side, and improve the immunity and resistance against students' frustration.

\subsection{EQ Helps Students to Establish Good Interpersonal Relationships}

Human are social beings. In the survival and development of human society, people must be in communication with others. Positive interpersonal relationships, multifaceted, multi-level and harmonious interpersonal relationship, will help students obtain essential personality, values, ideals, beliefs and social desirability behavior in social life, to speed up the process of socialization; It is able to help students to communicate with each other, make comparison, deepen the understanding of themselves; It could help students to get friendship, understanding and support, enhance the sense of self value and a sense of security, reduce the frustration, to maintain physical and mental health. Emotion plays a signaling role in the interpersonal relationship, and it is an important means of interpersonal communication. Cognition, expression and regulation of emotions, emotional awareness and understanding of others, and the improvement of emotional quotient, may help students to deal with interpersonal problems, establish harmonious interpersonal relationships, enhance interpersonal and social self-adaptability.

\subsection{EQ is Conducive to Physical and Mental Health of College Students}

The university stage is an important period of transition from students to adult gradually, and it is the peak of physical and mental development. Physical and psychological health is the guarantee for College students' growth. Emotions are closely related to the physical and mental health of college students. A healthy mood makes the students' whole body system and organ functions more coordinated, healthy, beneficial to the body health. It may also help students to get along with others better, have full of passion and creativity to learn, to work, to the life, and then have strength to overcome difficulties and setbacks. Bad mood will cause disorder in physiological function of college students, resulting in a variety of physical disease, inhibition of senior mental activity of cerebral cortex of students, so that their awareness of the normal range becomes narrow, less judgment, even lead to various neurological disorders and psychosis. EQ enable students to keep good mood through their emotional cognition, regulation, promoting their physical and mental health.

\section{Ways of Strengthening the Education of College Students' Emotional Quotient}

\subsection{Adjust and Optimize the Curriculum Structure, and Bring EQ Education into the University Curriculum Plan}

EQ and IQ are not opposite to each other, while there is a close relationship between them. The level of EQ has important influence on the development and perfection of IQ. Colleges and universities should pay more attention to the relationship among courses structure on the whole, bring EQ education into the curriculum plan, and set up the courses like moral education, humanistic quality education, marriage education, social education, occupation moral education, employment guidance education, public relations, psychology, management science and other courses related to emotional education. All of the above will be able to cultivate the students' world outlook, view of life and values, and to help them deal with the confusion in adaption to the environment, self management, interpersonal 
communication, friends, love, job hunting, the development of personality and emotion regulation. And then go on the healthy road of balanced development between IQ and EQ.

4.2 Strengthen the Construction of Campus Culture, and Create Good Atmosphere for the Education of Emotional Quotient

Strengthening the construction of campus culture, carrying out rich and colorful campus culture activities, is beneficial to creating a good atmosphere for EQ education and improving the level of students' emotional intelligence. For example, sports competitions, cultural activities, calligraphy and painting activities, organization of campus culture and art festival, the student cadre election, outing, volunteer activities, and so on. In these various forms of cultural activities in campus, students will be able to draw inspiration and obtain help through interaction, communication and emotional exchange with others. It will develop and strengthen students' healthy personality, and enable students to work in their own areas of strength talent, experience the joy of success, improve self-confidence, enhance competition and cooperation consciousness, enrich emotion, enhance interpersonal and communication relationship. In addition, the school should proceed from its own characteristics, guide and support students to make use of holidays to participate in various activities of social practice, social contact, understanding of society, put themselves to daily life or in the practice classroom, improve the student's sense of group honor, duty sense, moral sense, so as to enhance their Emotional Quotient.

\subsection{Improve Teachers' EQ Level, and Construct of High-EQ Teachers' Team}

EQ education is not only the need for comprehensive development of students, but also the need for teachers' teaching activities. Therefore, giving full play to the leading role of teachers is very important for the formation of good EQ education environment. Teachers, as the leadership in educational activities, should strive themselves to infect their educational objects with healthy and happy emotions, words and deeds, so as to produce a strong and positive inner experience, and thus transform their educational requirements into students' own motivation and need. Teachers should do body-teaching, and consciously influence the students through their own noble character, sentiment and good quality of the personality. In modern education, great changes have taken place in the role of teachers. Teachers have become guidance of knowledge and skills, psychological counselors and soul guide, not only a lecturer. As a teacher, he must improve his own level of EQ, and cultivate students with his high EQ level. Teachers should strive to form a high EQ group, and create a good environment for the EQ Education in school. In addition, the cognitive level of the teachers need to be strengthened, so that they could recognize the promoting effect of EQ education, thus teachers could consciously carry out EQ educationin their teaching practice.

4.4 Strengthen the Psychological Quality Education of College Students, Improve their Psychological Quality, and Train their Setback Ability

People's psychological quality is gradually formed and developed accompanied by the growth of human body. Strengthening the psychological quality education of College Students is very important for the development of College Students' EQ. Only if the psychological quality is improved, students could face the bad social phenomenon, could change pressure into motivation, and then grasp the social opportunities better. According to the characteristics that the psychological development of college students are not mature enough, college should be targeted to set up related courses, conduct awareness of mental health knowledge lectures, counseling services, and vigorously popularize mental health knowledge through the school journal, school radio station and campus network carrier. All of the above could guide students to control their emotions, enhance social adaptability, learn to deal with the contradiction between reality and desire, learn self-psychological adjustment, eliminate the psychological perplexity, and improve the ability to withstand setbacks. School and teachers should educate students to treat the success and failure correctly, and become good at drawing lessons from it, so as to help students to form healthy psychology.

\subsection{Establish Harmonious Interpersonal Relationships, and Develop Team Spirit}

College students should establish harmonious interpersonal relationships, develop the spirit of team cooperation, and continuously improve the level of EQ. First of all, teachers should pay attention to guide college students to establish harmonious relationship among students, make students realize that friendship is precious. Tolerance and cooperation is a virtue, and it is the essential quality for present and future society talent. Secondly, teachers should guide students to overcome inferiority complex, being confident to treat life, being open to people, and make his psychology relaxed and happy. Lastly, teachers should guide students to from the perspective of needs of others, consider matters from the perspective of the others' side, and thus learn to get along with other classmates, learn to be caring, understanding, sympathy, tolerant of others, be strict with themselves, be broad-minded toward others, to train students' spirit of unity and cooperation. 


\subsection{Establishment of Evaluation System of EQ Education}

An educational system can be established and continuously developed or not, is closely related to whether it has objective and scientific evaluation system. The education goal is achieved or not, could only be judged by evaluation. We already done enough research on the intelligence education, and established a scientific evaluation system, so it is relatively easy to get obvious results. However, owing to the psychological characteristics of emotional quotient, we could not accurately grasp the emotional value, unable to test and measure the effectiveness of education, resulting in that EQ education has no way to follow. We must gradually summarize a set of testing standards and means for EQ education practice. Timely EQ evaluation, and then identification, diagnosis, encouragement and supervision, will help students to control and regulate their emotions consciously and strictly, so as to achieve success.

\section{Conclusion}

The influence of Emotional Quotient is very significant for a person, while it is not innate, but is acquired after birth. The contemporary college students in the stage of mature but not fully mature. It is very necessary for Colleges and universities to strengthen college students' EQ Education. College students' emotional education should attach much importance. We should change the old education concept that IQ education is more important than EQ education. Today's society is full of opportunities and challenges, college students should not only have professional theory and professional knowledge, but also need to have a high level of emotional quotient. They should learn to do, learn to behave, to become a useful person with balanced development in the mind and the all-round personality. EQ education for college students should be cooperated closely with school, family, society, to form a resultant force of education.

\section{References}

Daniel Goleman. (1997). Emotional Quotient. Shanghai: Shanghai science and Technology Press.

Xinxing, Duan, \& Zhao Ling. (2003). Education of College Students' Mental Health. Beijing: Science Press.

Xiuling, Cai \& Zhixin, Yang. (2001). Emotional Management. Hefei: Anhui People's Publishing House.

Yun Ming, Hai. (1997). Emotional intelligence. Beijing: China City Publishing House.

Zhaolan, Meng. (2005). Emotional Psychology. Beijing: Peking University Press. 